\title{
SASKATCHEWAN BREEDING BIRD ATLAS 2017 SEASON HIGHLIGHTS
}

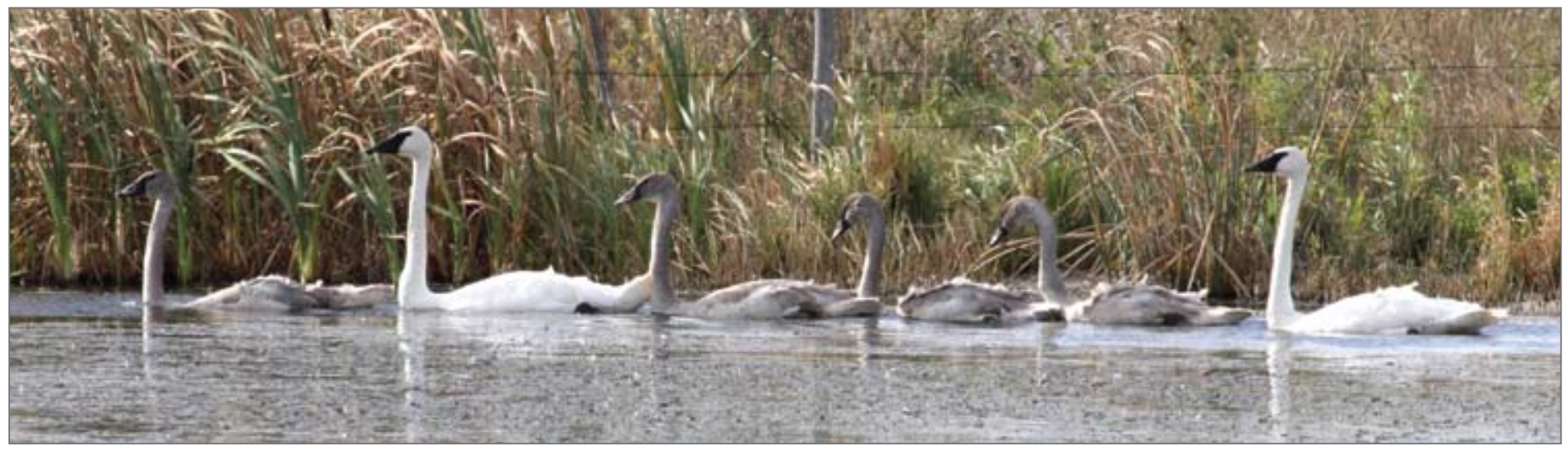

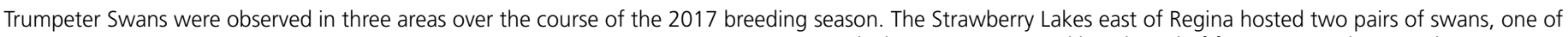
which was accompanied by a brood of five cygnets. Photo credit: Kim Mann

LeeAnn Latremouille and Kiel Drake skatlas@birdscanada.ca

The Saskatchewan Breeding Bird Atlas is off to a great start as data from the inaugural 2017 season continues to be submitted. Thanks to our intrepid volunteers and partners, breeding birds were documented from all four corners of the province, setting the pace for the years to come.

This five-year project (20172021) aims to document the distribution and relative abundance of Saskatchewan's breeding birds by harnessing the collective efforts of the birding/naturalist community, wildlife professionals, and private/ crown industries. Atlassers recorded observations of breeding birds and used a set of criteria to report on behaviours, ranging from birds that were simply "observed" to behaviours that suggest a bird is "possibly,"

"probably," or "confirmed" as a breeder. As in other jurisdictions, the province is divided into $10 \times 10 \mathrm{~km}$ atlas squares - a total of 6,914 squares in the province - in which the atlassers spend time searching to find as many species as possible.

To date, 235 atlas registrants have contributed 2,250 hours of survey effort reported from 628 atlas squares, documenting breeding behaviours for 252 species. The process of reviewing the resulting 35,000+ observations is underway and will give rise to discussions regarding the breeding intent of both common and rare birds that were encountered during the first field season. Currently, all records are provisional and subject to the review.

Progress maps are now available on the atlas website (sk.birdatlas.ca). Each species observed in the province has a map illustrating in which squares it has been detected and what level of breeding evidence was observed. The maps page also hosts summary statistics maps, such as the Hours of Survey Effort map shown in

Figure 1. Progress maps will update every two weeks during the summer, with intermittent updates occurring the rest of the year.

June 2017 was windy in

Saskatchewan, which made for poor point counting conditions over much of the province. Despite the uncooperative weather, atlassers still managed to complete an impressive 1,189 point counts. Point counts are critical to enable calculating estimates of relative abundance so we are hoping for better June weather conditions in the years to come to allow catching up on point counts.

Supplementing the point count effort was the use of bioacoustic technology, a first for Canada's national atlas program. Both handheld and autonomous recorders were used by volunteers and partners alike to make recordings of birdsong. Once analyzed, these recordings will provide data similar to that of an in-person point count. Several handheld recorders were recently purchased by the Atlas Office for upcoming years in hopes of empowering more atlassers to collect this critical information.

\section{Highlights}

The atlas got off to an unexpectedly early start in January 2017 when birders noticed White-winged Crossbills behaving unusually in southern regions of the province. A bumper crop of spruce cones in the south encouraged this nomadic species to breed, with breeding confirmed around Regina, Saskatoon, Broadview, Cypress Hills, Humboldt, Elrose and Edenwold.

The most widely encountered species, perhaps unsurprisingly, was the ubiquitous Red-winged Blackbird, having been reported from $\sim 63$ per cent (394) of the sampled atlas squares. Following closely behind were American Robin (58 per cent of squares), Mallard (53 per cent of squares), Barn Swallow (53 per cent of squares), and Clay-colored Sparrow (50 per cent of squares).

Trumpeter Swans were observed in three areas over the course of the breeding season. The Strawberry Lakes 
east of Regina hosted two pairs of swans, one of which was accompanied by a brood of five cygnets, confirming breeding. Pairs were also observed near Endeavour and on the southern portion of Hasbala Lake in the extreme northeastern corner of the province. Known haunts in the Cypress Hills and Greenwater Lake areas should be carefully searched in the upcoming years.

Other interesting sightings include Black-necked Stilts nesting in three atlas squares between Herbert and Chaplin and a male Black-throated Blue Warbler observed singing during a point count near Radisson. Near Eastend, a Sage Thrasher was observed singing in proximity to suitable nesting habitat, and Field Sparrows were heard singing in Grasslands National Park and south of Roche Percee. Regional Coordinators were surprised at the number of locations where the uncommon Orchard Oriole was detected and Common Ravens appear to be continuing their return to former ranges, further expanding out of the parkland and onto the plains with breeding confirmed in the Regina area.

Nearly 7,000 individuals of 26 species listed under the Species at Risk Act were reported to the atlas, including the endangered Greater Sage-Grouse, Sage Thrasher, Piping Plover, and Burrowing Owl. The recently listed Barn Swallow was the most commonly reported $(3,126$ individuals), followed by Bank Swallow (1,187 individuals) and Bobolink (605 individuals).

Partners at Environment and Climate Change Canada successfully completed several remote squares in northeastern Saskatchewan, providing much needed data from remote difficult-to-reach locations. Three multiday floatplane excursions provided crews with great birding opportunities; highlights include Surf Scoter, Mew Gull, Arctic Tern, Parasitic Jaeger, Gray-cheeked Thrush, Bohemian Waxwing, White-crowned Sparrow, Harris's Sparrow, Rusty Blackbird, and Common and Hoary Redpoll. Although a few of these species were not assigned breeding codes at time of observation, some may have been making nesting attempts and will no doubt provide the review committee with much to discuss!

The Saskatchewan Breeding Bird Atlas relies on the power of volunteer birders of all skill levels; if you are interested in contributing your observations to the project,

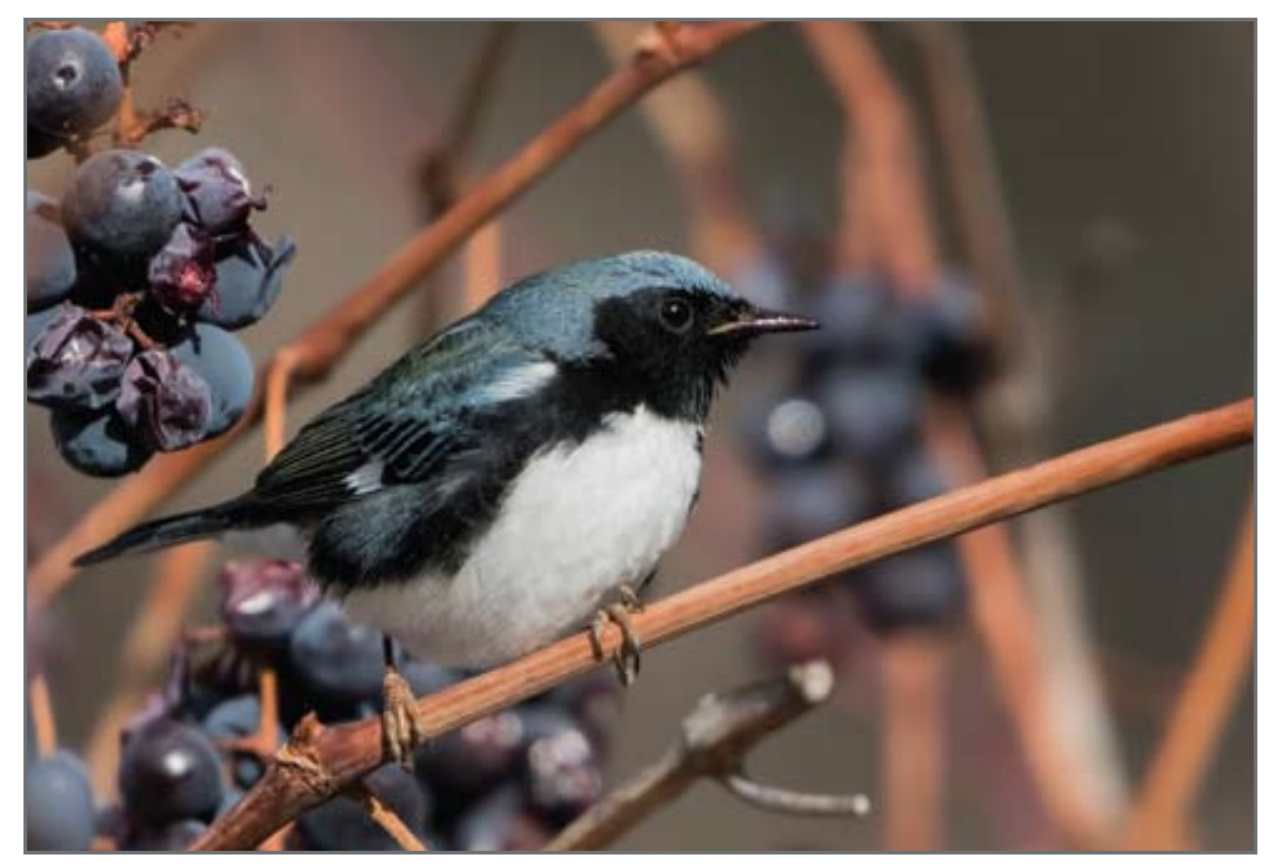

Male Black-throated Blue Warbler. Photo credit: Annie McLeod please consider joining us. For more information about the project and to register, view maps, and see upcoming events, visit the project website at sk.birdatlas.ca. The atlas team can be reached by phone at 306-249-2894 or by e-mail at skatlas@birdscanada.ca.

The Saskatchewan Breeding Bird Atlas is the result of a partnership between Bird Studies Canada, Environment and Climate Change Canada, the Saskatchewan Ministry of Environment, the Nature Conservancy of Canada, Nature Saskatchewan, and the Saskatchewan Wildlife Federation. Important financial support for the project comes from Environment and Climate Change Canada, the Saskatchewan Fish and Wildlife Development Fund, Mountain Equipment Co-op, Wildlife Habitat Canada, Weyerhaeuser, The McLean Foundation, Tolko Industries Itd., $\mathrm{K}+\mathrm{S}$ Potash Canada, and the Baillie Fund.
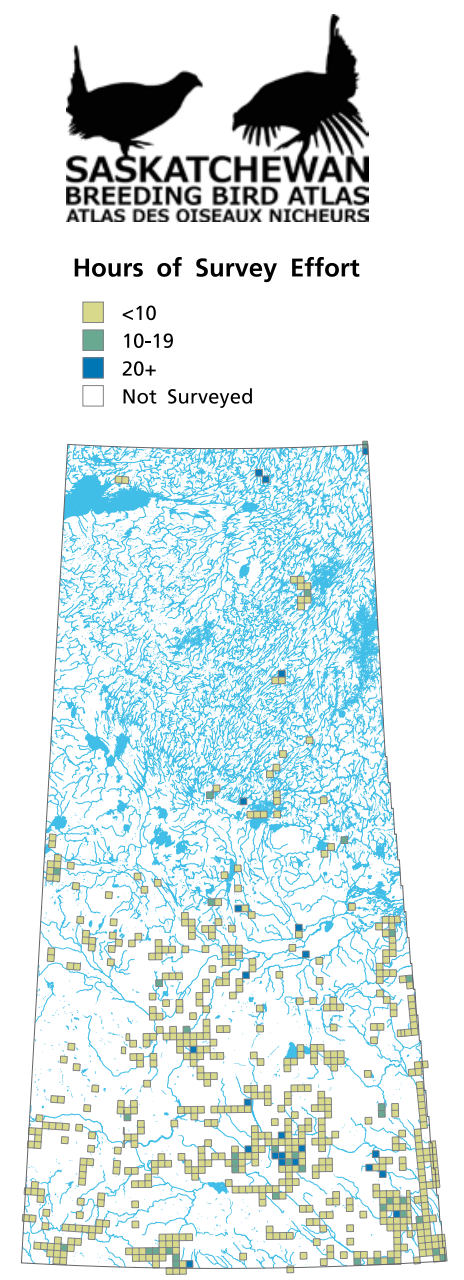

FIGURE 1. Hours of survey effort for the Saskatchewan Breeding Bird Atlas. 